Check for updates

Cite this: RSC Adv., 2017, 7, 33726

Received 19th May 2017

Accepted 30th June 2017

DOI: $10.1039 / \mathrm{c} 7 \mathrm{ra0} 5658 \mathrm{c}$

rsc.li/rsc-advances

\title{
Unique leafy morphology of poly(lactic acid) monoliths controlled via novel phase separation technology
}

\author{
Tomonari Kanno (iD) and Hiroshi Uyama*
}

\begin{abstract}
This work reports the unique leaf-like morphology and physical properties of plant-based poly(lactic acid) (PLA) monoliths designed by a novel thermally induced phase separation (TIPS) technology. PLA monoliths with micron to nano scale frameworks and a leaf-like morphology were successfully produced via TIPS with ternary solvent using 1,4-dioxane as a good solvent, water as a non-solvent, and 2-butanone as a midsolvent which controls phase separation. It was revealed for the first time that the addition of midsolvent significantly affects the morphology and crystallization of PLLA, which leads to a precise controllability in morphology and high porosity (90-93\%). A ternary phase diagram of the solvents was proposed for the TIPS, which successfully explained the present results. It was demonstrated that the newly developed, amazingly simple TIPS is ideal for the synthesis of PLA monoliths compared to the most commonly used TIPS with binary solvent
\end{abstract}

\section{Introduction}

Poly(lactic acid) (PLA) is a bio-based polymer with great biodegradability and biocompatibility, which is derived from renewable resources such as agricultural products and their byproducts including plant stem and leaf. Because of its environmental adaptability, PLA has received great attention for the development of a sustainable society. In addition to its biodegradability and biocompatibility, PLA has sufficient mechanical strength, high transparency, and processability due to its higher glass transition $\left(c a .60^{\circ} \mathrm{C}\right)$ and melting temperature $\left(c a .170^{\circ} \mathrm{C}\right)$ compared to other bio-based plastics. ${ }^{1}$ Moreover, PLA can be degraded by catalyst-free simple hydrolysis without toxic degradation products, for which PLA has been approved by the US Food and Drug Administration (FDA) for several medical uses. ${ }^{2,3}$ Because of these unique properties and great developments in the industrialization of PLA over decades, the use of PLA materials has been spread to various fields including medical, foods, packaging, and even housewares in different forms with increasing awareness to environmental conservation. ${ }^{4}$

Monolithic porous PLA has also been developed in several fields such as tissue engineering, drag delivering, and filtration technology. Since the monolith form of PLA has great advantages in surface area, light weight, and 3-D framework in addition to the environmental adaptability, the use of PLA monolith has been expanded to a scaffold for cultivating human cell, ${ }^{5}$ an artificial bone, ${ }^{6,7}$ a support for controlled release of

Department of Applied Chemistry, Osaka University, 2-1 Yamadaoka, Suita-shi, Osaka 565-0871, Japan. E-mail: uyama@chem.eng.osaka-u.ac.jp; Fax: +8106 6879 7367; Tel: +810668797364 drugs, ${ }^{2,8}$ and a filter. ${ }^{9-11}$ The monolith formation has been developed using a variety of methods including porogen, fiber bonding, gas-based foaming, a use of supercritical $\mathrm{CO}_{2}$, and 3-D printing. ${ }^{2,5,12-14}$ Especially, for the usage mentioned above, it is important to synthesize monoliths through the process with precise controllability in morphology and reproducibility because the function of monoliths such as biodegradation rate, hydrophobicity, and adhesiveness significantly depends on its pore and skeletal size. Therefore, exploring a method with process flexibility has been attempted to prepare desirable formation suitable for each usage.

Among those techniques of producing PLA monoliths, recently, phase separation has been utilized due to its excellent versatility, simplicity, and controllability in pore size compared to other methods. ${ }^{9-11,15-19}$ Furthermore, good processability is also key factor of this method since the shape of monolith is dependent on the shape of vessels where the phase separation and gelation take place. This method can mainly be classified into two for preparation of monoliths from PLA by types of trigger to occur phase separation: non-solvent induced phase separation (NIPS) and thermally induced phase separation (TIPS). These techniques were previously explained in detail by Lloyd et al. using the Flory-Huggins theory. ${ }^{20,21}$ Briefly, the change in polymer fraction in a ternary system of polymer, good solvent, and non-solvent increases Gibbs free energy which triggers phase separation. Until the mixing of polymer-lean and polymer-rich phases becomes stable, phase separation continues to satisfy the lowest Gibbs free energy. At this process, the system undergoes liquid-liquid or solid-liquid phase separation depending on the composition and temperature, which determines the final morphology of monoliths. It is well 
known that liquid-liquid phase separation gives interpenetrating 3-D network via spinodal decomposition, whereas solid-liquid phase separation leads to the sea-island morphology including polymer precipitation via nucleation and growth mechanism. ${ }^{21}$

In the NIPS method, addition of non-solvent to polymer solution induces phase separation. ${ }^{\mathbf{2 0 , 2 1}}$ The morphology of obtained monoliths can be changed by various factors such as selection of solvent and polymer, solvent ratios, polymer concentration, molecular weight, and standing temperature. Few researchers attempted to produce PLA monoliths by NIPS. ${ }^{15,16}$ For example, Rezabeigi et al. produced PLA monoliths by NIPS using dichloromethane (DCM) as a polymer solvent and hexane as a non-solvent. ${ }^{15}$ They reported that PLA monoliths with the porosity ranging from $40.7 \%$ to $90.7 \%$ and meso/ macroporous hierarchical morphology were successfully fabricated by changing the DCM ratio and the PLA concentration during phase separation.

By contrast, TIPS method has also been utilized to prepare PLA monolith. ${ }^{9-11,17-19}$ In the TIPS method, the drop in polymer solubility induced by solution temperature leads phase separation. Distinct from NIPS process, TIPS has remarkable advantages in reproducibility and flexibility since the phase separation is occurred by simple temperature reduction rather than non-solvent exchange which include variables that need to be controlled. ${ }^{20}$ Furthermore, the morphology can be controlled by changing quench temperature in addition to those controlling factors of NIPS as mentioned. Despite these fascinating advantages, the precise control to give desirable morphology of PLA monoliths via TIPS is still challenge. For instance, Tanaka et al. applied this method and reported that PLA monoliths for filtration could be prepared by the TIPS using 1,4-dioxane as a solvent and water as a non-solvent, ${ }^{9}$ however, the resultant PLA monoliths mainly exhibited pores in the short range of 10$30 \mu \mathrm{m}$ with micron scale of frameworks. On the other hand, Önder et al. developed this idea and reported that PLA monoliths with high porosity ranging from 85.1 to $92.8 \%$ and $25-400$ $\mu \mathrm{m}$ of relatively large pores were fabricated using tetrahydrofuran (THF) and water solvent system by changing polymer concentration, solvent ratio, and quenching temperature. ${ }^{17}$ Although they conducted to control the morphology with various ways, the pore and skeletal size of PLA monoliths were still limited in the micron scale.

In our present study, we focused on the production of PLA monolith with micron to nano scale of pore and skeletal size via novel TIPS method using ternary solvent, elucidating the relationships between structures and characteristics via phase diagram in the system and thermo-analysis. Distinct from the traditional TIPS using binary solvent, we selected ternary solvents: 1,4-dioxane as a good solvent, water as a non-solvent, and 2-butanone as a mid-solvent which controls phase separation. 2-Butanone was chosen because it exhibits good affinity but no solubility to PLA itself in addition to miscibility with 1,4dioxane/water. We demonstrate that the PLA monoliths with unique morphology and precise controllability in pore and skeletal size can be fabricated by amazingly simple, newly developed TIPS.

\section{Experimental section}

\section{Materials}

Poly(L-lactic acid) (PLLA) was purchased from NatureWorks LLC (Ingeo $^{\mathrm{TM}}$ Biopolymer $4032 \mathrm{D}, M_{\mathrm{w}}=1.5 \times 10^{5} \mathrm{~g} \mathrm{~mol}^{-1}$ ). 1,4Dioxane, 2-butanone, and 2-propanol (iPA) were obtained from Nacalai tescue and were used as received.

\section{Ternary phase diagram}

For understanding detailed behaviors on phase separation, we prepared ternary phase diagram of 1,4-dioxane/2-butanone/ water at fixed PLLA concentration and temperature by changing the ratio of solvents to give a cloud point of the solution.

First, PLLA was dissolved in 1,4-dioxane/2-butanone mixture at $70{ }^{\circ} \mathrm{C}$ with the PLLA concentration of $100 \mathrm{mg} \mathrm{mL}^{-1}$ for $2 \mathrm{~h}$ in a glass test jaw. After dissolution, water was added to the solution and then the transparent solution was kept at $70{ }^{\circ} \mathrm{C}$ or $0{ }^{\circ} \mathrm{C}$ for $30 \mathrm{~min}$. The cloud point in the system at $70{ }^{\circ} \mathrm{C}$ and $0{ }^{\circ} \mathrm{C}$ was defined at which the solution turned opaque during $30 \mathrm{~min}$. By plotting these cloud points, the borders separated homogenous and heterogenous area at $70{ }^{\circ} \mathrm{C}$ and $0{ }^{\circ} \mathrm{C}$ in the system were determined.

\section{Preparation of PLA monoliths}

At first, PLLA was dissolved in 1,4-dioxane/2-butanone mixture at $70{ }^{\circ} \mathrm{C}$ with the PLLA concentration of $100 \mathrm{mg} \mathrm{mL}^{-1}$ for $2 \mathrm{~h}$ in a glass test jaw. Then, water was added to the solution and stirred for $10 \mathrm{~min}$ to give transparent solution. The ratios of ternary solvent were selected from homogenous region surrounded by the boundaries at $70{ }^{\circ} \mathrm{C}$ and $0{ }^{\circ} \mathrm{C}$ in the ternary phase diagram (Table 1), that is, wherein the homogenous solution at $70{ }^{\circ} \mathrm{C}$ can be phase-separated by quenching to $0{ }^{\circ} \mathrm{C}$. The solution was immediately cooled to $0{ }^{\circ} \mathrm{C}$ using ice bath for $1 \mathrm{~h}$ to induce phase separation. The resultant gels were exchanged to iPA by washing using a TAITEC BioShaker M-BR$022 \mathrm{UP}$ at $25{ }^{\circ} \mathrm{C}$. The obtained gels were placed in a vacuum and dried at room temperature for $5 \mathrm{~h}$ to give PLLA dry-monolith. Fig. 1 shows the sample at each process in this study. Additionally, to investigate the influence of PLLA concentration on the formation of PLLA monoliths in the system, extra monoliths

Table 1 Ratio of ternary solvent (1,4-dioxane/2-butanone/water) and PLLA concentration used in the process

\begin{tabular}{lllll}
\hline Systems $^{a}$ & $\begin{array}{l}\text { 1,4-Dioxane } \\
(\mathrm{v} / \mathrm{v} \%)\end{array}$ & $\begin{array}{l}\text { 2-Butanone } \\
(\mathrm{v} / \mathrm{v} \%)\end{array}$ & $\begin{array}{l}\text { Water } \\
(\mathrm{v} / \mathrm{v} \%)\end{array}$ & $\begin{array}{l}\text { PLLA conc. } \\
\left(\mathrm{mg} \mathrm{mL}^{-1}\right)\end{array}$ \\
\hline $85 / 0 / 15$ & 85.0 & 0 & 15.0 & 100 \\
$65 / 20 / 15$ & 65.0 & 20.0 & 15.0 & 100 \\
$45 / 40 / 15$ & 45.0 & 40.0 & 15.0 & 100 \\
$25 / 60 / 15$ & 25.0 & 60.0 & 15.0 & 100 \\
$20 / 70 / 10$ & 20.0 & 70.0 & 10.0 & 100 \\
$15 / 80 / 5$ & 15.0 & 80.0 & 5.0 & 100 \\
$10 / 90 / 0$ & 10.0 & 90.0 & 0 & 100
\end{tabular}

${ }^{a}$ System corresponds to the solvent ratio of 1,4-dioxane/2-butanone/ water $(\mathrm{v} / \mathrm{v} \%)$ 
(a)

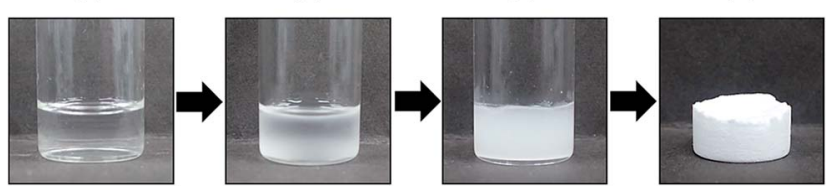

Fig. 1 Fabrication process of PLLA monoliths in this study: PLLA solution (a), solution undergone phase separation (b), wet gel resulted from gelation (c), PLLA monolith after drying (d).

were prepared using the same technique mentioned above at fixed (15/80/5) 1,4-dioxane/2-butanone/water ratio with different PLLA concentrations (50-150 $\mathrm{mg} \mathrm{mL}^{-1}$ ).

\section{Analysis}

Morphology of PLLA monoliths were observed by scanning electron microscopic (SEM) analysis using a HITACHI SU-3500 instrument. Averaged pore diameter was determined using Image-Pro PLUS (MediaCybernetics) by calculating to 50 pores exhibited in the SEM image of the monoliths. Melting temperature $\left(T_{\mathrm{m}}\right)$, and crystallinity $\left(X_{\mathrm{c}}\right)$ of the PLLA monoliths and the pellet used were estimated by differential scanning calorimetry (DSC) using SEIKO DSC6220, at a heating rate of $10^{\circ} \mathrm{C} \mathrm{min}^{-1}$ in a range between 30 and $200^{\circ} \mathrm{C}$ and a nitrogen flow rate of $50 \mathrm{~mL}$ $\min ^{-1}$. The crystallinity of the PLLA crystals were calculated using the theoretical heat of fusion $\left(93.1 \mathrm{~J} \mathrm{~g}^{-1}\right){ }^{22}$ During the DSC measurements, no peaks ascribable to cold crystallization appeared so that the $X_{\mathrm{c}}$ could be simply estimated from the enthalpy of melting. Porosity of the monoliths was calculated using an apparent density of the monoliths and eqn (1) given below. ${ }^{15,23}$

$$
\text { Porosity }(\%)=\left(1-\frac{\rho}{\rho_{0}}\right) \times 100
$$

here, $\rho / \rho_{0}$ represents the relative density where $\rho$ and $\rho_{0}$ are respectively the apparent density and skeletal density which can be estimated from eqn (2)

$$
\rho_{0}=w_{\mathrm{c}}\left(\rho_{\mathrm{c}}-\rho_{\mathrm{a}}\right)+\rho_{\mathrm{a}}
$$

In the eqn (2), where $w_{\mathrm{c}}$ represents the crystalline volume ratio, $\rho_{\mathrm{c}}$ is the density of $100 \%$ crystalline PLLA $\left(1.290 \mathrm{~g} \mathrm{~cm}^{-3}\right)$, and $\rho_{\mathrm{a}}$ is the density of fully amorphous PLLA (1.248 g $\left.\mathrm{cm}^{-3}\right) \cdot{ }^{15,22,23}$ Thus, the $\rho_{0}$ can be estimated by measuring the crystallinity of the PLLA monoliths using DSC.

\section{Results and discussion}

\section{Ternary phase diagram}

Fig. 2 gives the ternary phase diagram of 1,4-dioxane/2butanone/water at PLLA concentration of $100 \mathrm{mg} \mathrm{mL}^{-1}$. As shown from the diagram, the PLLA solution become heterogenous over $91 \mathrm{v} / \mathrm{v} \%$ of 2 -butanone and $17 \mathrm{v} / \mathrm{v} \%$ of water contents at $70{ }^{\circ} \mathrm{C}$, whereas those of maximum contents at $0{ }^{\circ} \mathrm{C}$ are decreased to $60,11 \mathrm{v} / \mathrm{v} \%$, respectively. In this regard, phase separation takes place by quenching from $70{ }^{\circ} \mathrm{C}$ to $0{ }^{\circ} \mathrm{C}$ using

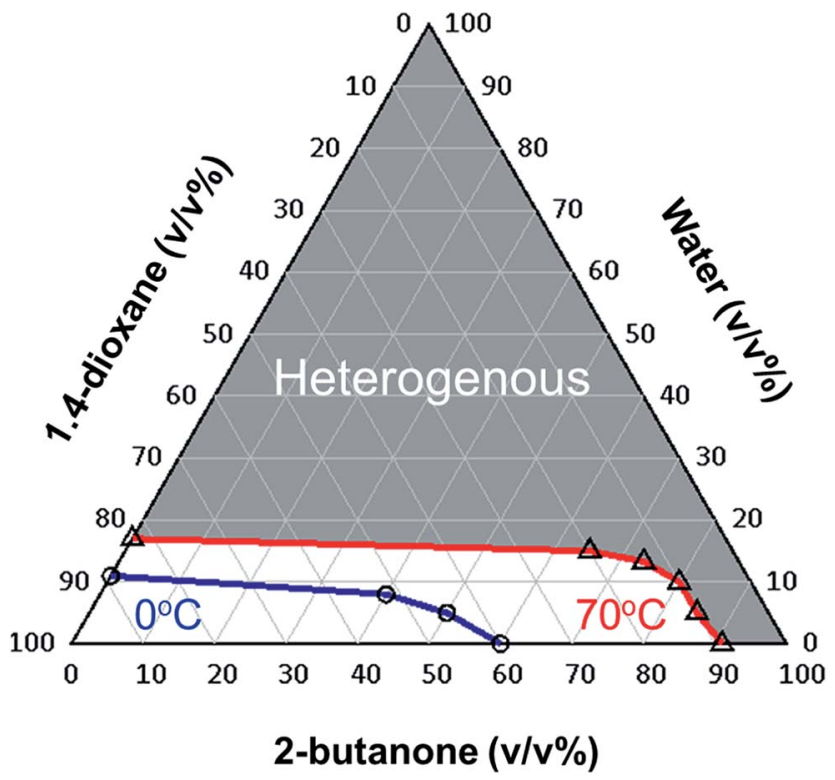

Fig. 2 Ternary phase diagram of 1,4-dioxane/2-butanone/water system with the fixed PLLA concentration at $100 \mathrm{mg} \mathrm{mL}^{-1}$. Note that $(\triangle)$ and $(O)$ symbols represent respectively the cloud point in the system at $70^{\circ} \mathrm{C}$ and $0{ }^{\circ} \mathrm{C}$. The boundaries separated homogenous and heterogenous (area in grey) regions at $70^{\circ} \mathrm{C}$ and $0{ }^{\circ} \mathrm{C}$ in the system are given in red and blue lines, respectively.

the solvent ratio selected from the region surrounded by homo/ heterogenous boundaries at $70^{\circ} \mathrm{C}$ and $0^{\circ} \mathrm{C}$. It is noteworthy that the region between boundaries at $70{ }^{\circ} \mathrm{C}$ and $0{ }^{\circ} \mathrm{C}$ become significantly wider with increasing the ratio of 2-butanone, whereas that in the binary 1,4-dioxane/water system is limited in narrow range between $89 / 11$ and $83 / 17 \mathrm{v} / \mathrm{v} \%$. These data indicate that PLLA is much more miscible in the ternary 1,4dioxane/2-butanone/water solvent than the traditional binary 1,4-dioxane/water solvent, suggesting the slower phase separation can be occurred in the solution with higher 2-butanone content. This effect of phase separation will be discussed in detail later.

Furthermore, this study demonstrates that the addition of mid-solvent may expand selection of controlling factor for pore and skeletal size. For over decades, TIPS with binary good/poor solvent have been widely used, ${ }^{9-11,17-19}$ while this often limits the condition of fabrication. For example, Tanaka et al. reported that PLLA monoliths were produced by TIPS using binary 1,4dioxane/water solvent with the limited ratio around 87/13 w/ $\mathrm{w} \%$ at $10 \mathrm{wt} \%$ of PLLA concentration. ${ }^{9}$ In addition, Önder $e t$ al. reported PLLA monoliths were successfully fabricated using binary $\mathrm{THF} /$ water solvent, however, only narrow range of the $\mathrm{THF} /$ water ratio between $90 / 10$ and $84 / 16 \mathrm{w} / \mathrm{w} \%$ can be utilized to give the monolith formation. ${ }^{17}$ Therefore, the TIPS using ternary solvent in this study may open the limitation in choice of solvent to add a desirable morphology to monoliths.

\section{Characterization of PLLA monoliths}

PLLA monoliths with no visible shrinkage after drying were successfully produced from fully gelated PLLA gels synthesized 
Table 2 Physical properties of PLLA monoliths prepared at different 1,4-dioxane/2-butanone/water ratios

\begin{tabular}{lllll}
\hline Systems $^{a}$ & $T_{\mathrm{m}}{ }^{b}\left({ }^{\circ} \mathrm{C}\right)$ & $X_{\mathrm{c}}{ }^{c}(\%)$ & $\begin{array}{l}\text { Apparent density } \\
\left(\mathrm{g} \mathrm{cm}^{-3}\right)\end{array}$ & Porosity $^{d}(\%)$ \\
\hline $85 / 0 / 15$ & 168.0 & 45.0 & 0.12 & 90 \\
$65 / 20 / 15$ & 168.2 & 54.9 & 0.12 & 91 \\
$45 / 40 / 15$ & 168.5 & 57.4 & 0.11 & 92 \\
$25 / 60 / 15$ & 170.1 & 58.5 & 0.10 & 92 \\
$15 / 80 / 5$ & 168.7 & 66.5 & 0.10 & 93
\end{tabular}

${ }^{a}$ System corresponds to the solvent ratio of 1,4-dioxane/2-butanone/ water $(\mathrm{v} / \mathrm{v} \%) .{ }^{b} T_{\mathrm{m}}=$ melting temperature of PLLA crystal. ${ }^{c} X_{\mathrm{c}}=$ crystallinity of PLLA crystal calculated from DSC measurements assuming the theoretical heat of fusion $=93.1 \mathrm{~J} \mathrm{~g}^{-1} \cdot{ }^{22}{ }^{d}$ Porosity calculated from eqn (1) and (2) using the apparent density and crystallinity of PLLA monoliths.

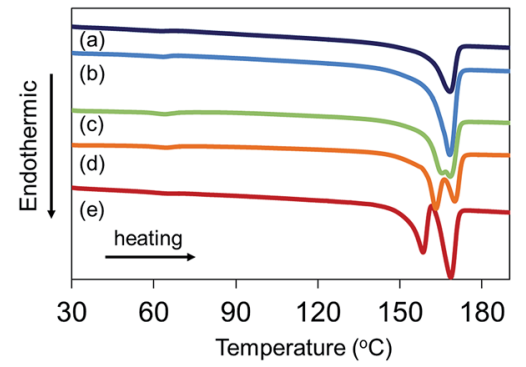

Fig. 3 DSC thermograms of PLLA monoliths prepared at different 1,4dioxane/2-butanone/water ratios [(a) 85/0/15, (b) 65/20/15, (c) 45/40/ 15 , (d) $25 / 60 / 15$, (e) $15 / 80 / 5]$.

at the all solvent ratios used which is determined by the ternary diagram. The resultant samples were analyzed by DSC to estimate PLLA crystallinity and porosity of the monoliths, focusing on the influence of the solvent ratio.
In Table 2 and Fig. 3 showing the DSC results, all PLLA monoliths indicated the $T_{\mathrm{m}}$ peak originated from PLLA crystals at $c a .168{ }^{\circ} \mathrm{C}$, which corresponded to $45.0-66.5 \%$ of high crystallinity. Note that the crystallinity become higher with increasing the ratio of 2-butanone which was used in the TIPS process. This can be explained by the difference in speed of phase separation, which is previously discussed in detail by several researchers. ${ }^{15,17}$ During quenching process, the phase separation and the gelation caused by crystallization of PLLA are occurred competitively. The crystallization takes place in the polymer rich phase during liquid-liquid phase separation, wherein the solvent diffuses from the polymer-rich phase to lean phase giving the mobility of polymer chain. Namely, the lower phase separation rate is, the slower solvent transport from the polymer-rich phase takes place, which provides sufficient time to form more crystals. Therefore, the speed of phase separation in the system significantly affects on the final morphology and crystallinity of the resultant PLLA monoliths. In this study, as the 2-butanone ratio in the mixture increases, the slower phase separation can be occurred providing more time to facilitate PLLA crystallization during quenching because of its higher miscibility of PLLA than that mixture including larger amount of water (see Fig. 2). It is also interesting to note that all PLLA monoliths exhibited much higher crystallinity than original PLLA pellet $\left(X_{\mathrm{c}}=38.9 \%\right)$ used for preparing the monoliths. This tendency has been also reported previously when using other choices of polymer, ${ }^{24}$ however, the mechanism of the crystallization during phase separation has not been fully investigated until now. In the present study, a possible cause of the higher PLLA crystallinity may be induced by the ordering and/or stretching of the polymer chain during phase separation, promoting the formation of PLLA crystallization.
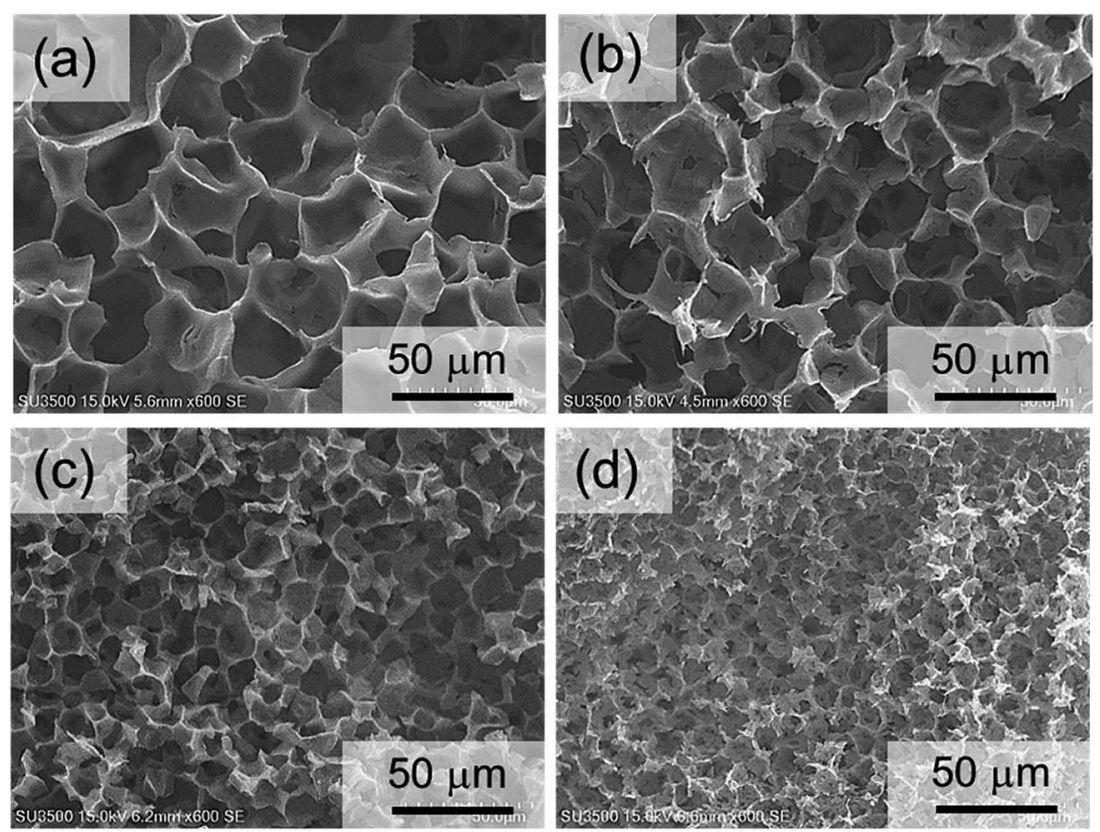

Fig. 4 SEM images of PLLA monoliths prepared from different 1,4-dioxane/2-butanone/water ratios [(a) 85/0/15, (b) 65/20/15, (c) 45/40/15, (d) 25/60/15] 
From the estimated PLLA crystallinity, the porosity of all monoliths were successfully calculated from the eqn (1) and (2) using the apparent density (Table 2). These calculations demonstrated that the PLLA monoliths have more than $90 \%$ of high porosity, and was increased from 90 to $93 \%$ with higher 2 butanone content. The increase in porosity may due to the shrinkage at gelation process for the system including larger amount of water. During gelation, water can exist on the hydrophilic surface of the glass test container, which can lead to the shrinkage preventing the gel formation at the edge of glass. This tendency is often observed in TIPS process with other choices of solvents in our researching group.

Thus, it was revealed that the PLLA monoliths with the high crystallinity and porosity were successfully fabricated through the controlled phase separation using 2-butanone.

\section{Morphology control of PLLA monoliths}

Structural analysis was carried out to observe the morphology of PLLA monoliths (Fig. 4 and 5). SEM images demonstrated that all samples exhibited 3-D porous structure which was frozen by phase separation. Fig. 4 clearly shows that the wall-like morphology was minimized self-similarly with increasing the ratio of 2-butanone at the range of (1,4-dioxane/2-butanone/ water) $85 / 0 / 15$ to $25 / 60 / 15$ (v/v\%) fixing water content. In addition, in the range of $25 / 60 / 15$ to $10 / 90 / 0$ (v/v\%), with the collapse of wall-like morphology, pore and skeletal size in the PLLA monoliths were decreased dramatically with higher 2-butanone content and given unique morphology in which leaf-like small units were interconnected (Fig. 5). From these SEM images, the averaged pore size of the monoliths was calculated by collecting each pore diameters (Fig. 6). Amazingly, the averaged pore size was diminished drastically from $28.6 \mu \mathrm{m}$ to $1.1 \mu \mathrm{m}$ by only

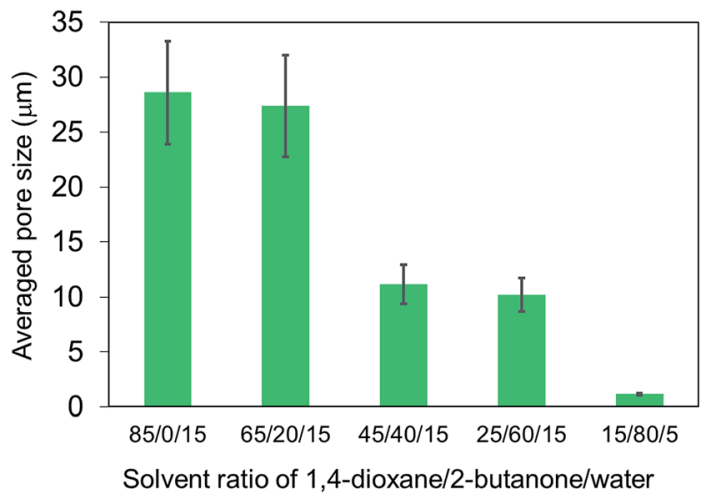

Fig. 6 Change in averaged pore size of PLLA monoliths prepared at different 1,4-dioxane/2-butanone/water ratios calculated from SEM images shown in Fig. 4 and 5.

changing the solvent ratio, where the skeletal size was also decreased from $2500 \mathrm{~nm}$ to less than $200 \mathrm{~nm}$. These descents in size can also be explained by the speed of phase separation and the crystallization of PLLA mentioned above. The slower phase separation induced by higher content of 2-butanone promotes PLLA crystallization (see Table 2) that leads higher viscosity in the system and arrests phase separation in earlier stage, resulting in shorter gelation time and gel formation with minimized morphology. ${ }^{15}$

For comparison with other controlling factors than the 2-butanone ratio, it was additionally investigated the effect of PLLA concentration on monolith formations (Fig. 7). PLLA monoliths were successfully produced at fixed (15/80/5) 1,4dioxane/2-butanone/water ratio with the limited PLLA concentration of $c a$. $50-150 \mathrm{mg} \mathrm{mL}^{-1}$, whereas that prepared from less than 50 or over $150 \mathrm{mg} \mathrm{mL}^{-1}$ resulted in polymer precipitate
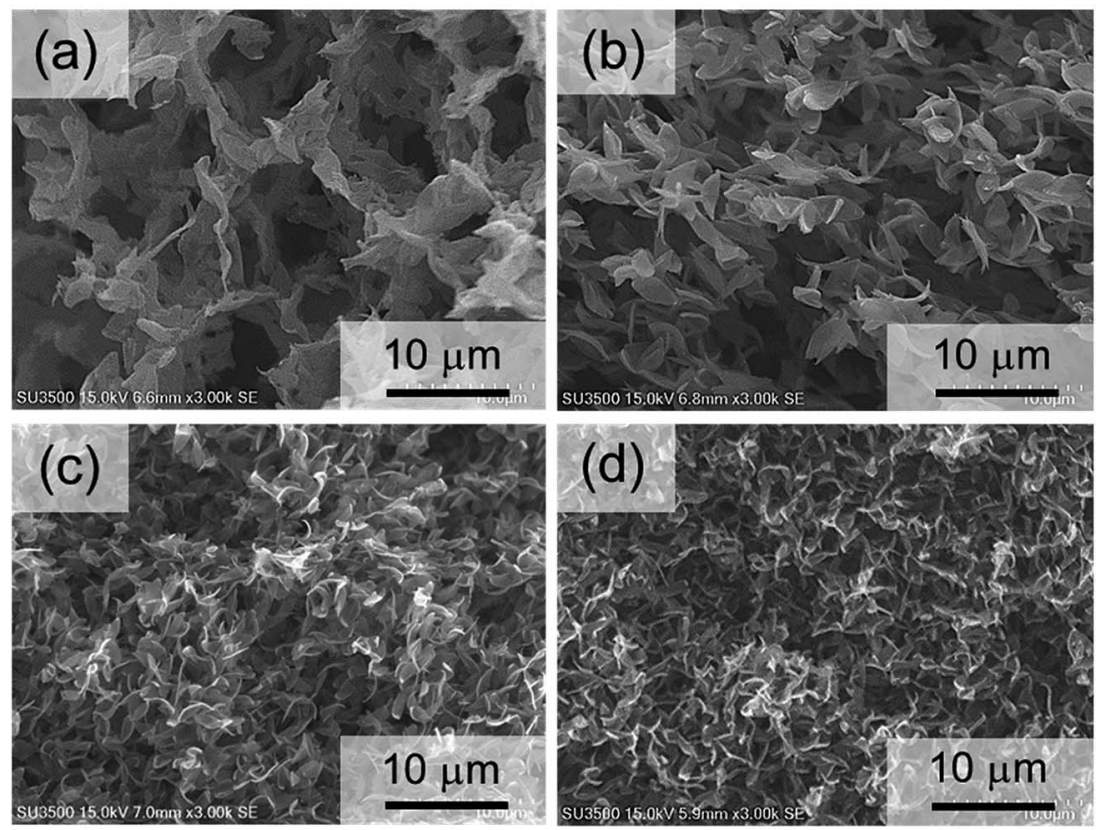

Fig. 5 SEM images of PLLA monoliths prepared from different 1,4-dioxane/2-butanone/water ratios [(a) 25/60/15, (b) 20/70/10, (c) 15/80/5, (d) 10/90/0] with high resolution. 

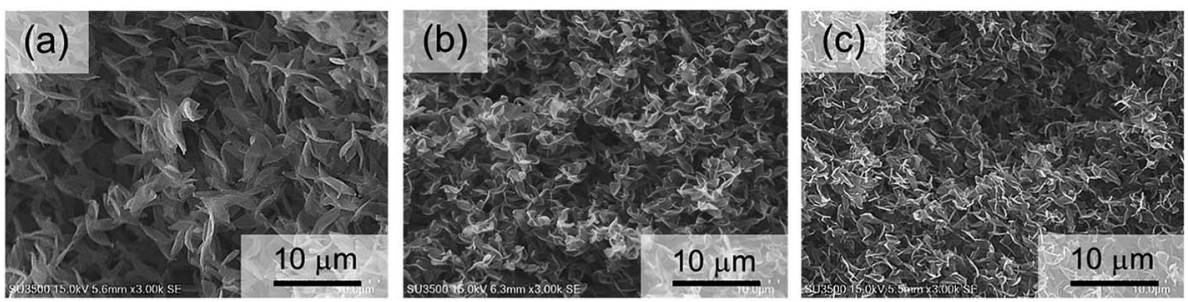

Fig. 7 SEM images of PLLA monoliths prepared at (15/80/5) 1,4-dioxane/2-butanone/water with different PLLA concentration [(a) 50 mg mL ${ }^{-1}$, (b) $100 \mathrm{mg} \mathrm{mL}^{-1}$, (c) $150 \mathrm{mg} \mathrm{mL}^{-1}$.

after quenching or heterogenous solution before the phase separation process. SEM observation clearly demonstrated that the leafy framework in the monoliths was minimized with increasing the concentration of PLLA, however, the change on morphology was occurred in narrow scope compared to the variations generated by 2-butanone content. This fact may indicate that the influence of the amount of 2-butanone on phase separation is more critical in the system than the change in PLLA concentration.

In the past, PLLA monoliths produced from common TIPS method using binary solvent tended to have micron scale of wall-like morphology because of the fast phase separation given by absence of the solvent which controls the phase separation and PLLA crystallization efficiently. ${ }^{9,17}$ In the present study, PLLA monoliths having micron to nano meter scale of pore and skeletal sizes with leaf-like morphology were successfully produced by only changing the ternary solvent ratio using 2butanone as the controlling factor of TIPS. It was demonstrated that the novel TIPS method using ternary solvent including 2butanone is ideal for the synthesis of PLLA monoliths compared to the more commonly used binary solvent.

\section{Conclusions}

This work utilized for the first time that the TIPS using novel ternary solvent of 1,4-dioxane/2-butanone/water to fabricate PLLA monoliths with excellent controllability in morphology. The influence of the addition of 2-butanone as a controlling factor was elucidated from the ternary phase diagram of the solvents and characterization of the resultant monoliths, focusing on the relationships between its structure and characteristics. It was demonstrated that 2-butanone in the 1,4dioxane/water mixture significantly affects the morphology and crystallinity of PLLA monoliths. Furthermore, it was revealed that 2-butanone is capable of promoting the slow phase separation which leads the diminished structure. Besides, the addition of mid-solvent expands the selection of solvent condition, which enables precise control in morphology just by changing the ratio of the solvents without any controlling factors such as polymer concentration, molecular weight, and quenching temperature. The ternary phase diagram proposed for the TIPS in this study successfully explains the present results. The PLLA monoliths exhibited micron to nano scale of pore (28.6-1.1 $\mu \mathrm{m})$ and skeletal (2500-200 $\mathrm{nm}$ ) size with high porosity up to $90-93 \%$ were successfully obtained by only changing the starting solvent ratios during phase separation. Moreover, it was observed that the unique transition to interconnected leaf-like structure from wall-like morphology with increasing the content of 2-butanone. Thus, it was demonstrated that the PLLA monoliths with unique morphology and precise controllability in pore and skeletal size can be fabricated by newly developed TIPS.

\section{References}

1 Y. Ikada and H. Tsuji, Macromol. Rapid Commun., 2000, 21, 117.

2 G. B. Jacobson, R. Shinde, C. H. Contag and R. N. Zare, Angew. Chem., Int. Ed., 2008, 47, 7880.

3 E. Rezabeigi, P. M. Wood-Adams and R. A. L. Drew, Polymer, 2014, 55, 3100.

$4 \mathrm{~K}$. Oshima, in Technology and Market Development of Green Plastic Polylactide (PLA), Frontier Publishing Co., Ltd, Japan, 2005, pp. 3-12.

5 C. Liu, H. M. Wong, K. W. K. Yeung and S. C. Tjong, Polymers, 2016, 8, 287.

6 K. Rezwan, Q. Z. Chen, J. J. Blaker and A. R. Boccaccini, Biomaterials, 2006, 27, 3413.

7 A. Obata, H. Ozasa, T. Kasuga and J. R. Jones, J. Mater. Sci.: Mater. Med., 2013, 24, 1649.

8 B. Tyler, D. Gullotti, A. Mangraviti, T. Utsuki and H. Brem, Adv. Drug Delivery Rev., 2016, 107, 163.

9 T. Tanaka and D. R. Lloyd, J. Membr. Sci., 2004, 238, 65.

10 T. Tanaka, S. Eguchi, T. Aoki, T. Tamura, H. Saitoh, M. Taniguchi, H. Ohara, K. Nakanishi and D. R. Lloyd, Biochem. Eng. J., 2007, 33, 188.

11 T. Tanaka, T. Nishimoto, K. Tsukamoto, M. Yoshida, T. Kouya, M. Taniguchi and D. R. Lloyd, J. Membr. Sci., 2012, 396, 101.

12 A. G. Mikos, A. J. Thorsen, L. A. Czerwonka, Y. Bao, R. Langer, D. N. Winslow and J. P. Vacanti, Polymer, 1994, 35, 1068.

13 M. Nofar and C. B. Park, Prog. Polym. Sci., 2014, 39, 1721.

14 T. Serra, J. A. Planell and M. Navarro, Polymer, 2013, 9, 5521.

15 E. Rezabeigi, P. M. Wood-Adams and R. A. L. Drew, Polymer, 2014, 55, 6743.

16 A. Gao, Y. Zhao, Q. Yang, Y. Fu and L. Xue, J. Mater. Chem. A, 2016, 4, 12058.

17 Ö. C. Önder, E. Yilgöl and I. Yilgöl, Polymer, 2016, 107, 240. 
18 G. A. Mannella, F. C. Pavia, V. L. Carrubba and V. Brucato, Eur. Polym. J., 2016, 79, 176.

19 T. Nie, M. He, M. Ge, J. Xu and H. Ma, Appl. Polym. Sci., 2017, 134, 44885.

20 D. R. Lloyd, S. S. Kim and K. E. Kinzer, J. Membr. Sci., 1991, 64, 1.
21 D. R. Lloyd, K. E. Kinzer and H. S. Tsung, J. Membr. Sci., 1990, 52, 239.

22 E. W. Fischer, H. J. Sterzel and G. Wegner, Kolloid Z. Z. Polym., 1973, 251, 980.

23 P. X. Ma and R. Y. Zhang, J. Biomed. Mater. Res., 1999, 46, 60. 24 Y. Xin, T. Fujimoto and H. Uyama, Polymer, 2012, 53, 2847. 